\title{
Study on the Main Obstacles and Countermeasures of the Inheritance and Development of Chinese Minority in Traditional Sports
}

\author{
Yanhong Wang \\ Sanya Aviation \& Tourism College, Sanya, Hainai, 572000
}

Keywords: Obstacles and Countermeasures, Inheritance and Development, Traditional Sports

\begin{abstract}
Minority traditional sports culture is an important part of ethnic culture. As a cultural symbol or cultural activity, it contains the national unique national spirit, value recognition, psychological mode and production and lifestyle. Minority traditional sports culture inheritance exists in the competitive and light mass, heavy form and light connotation, heavy tradition and light of modernity and minority inheritance and lack of succession of traditional sports inheritance and other issues, therefore, should be from the correct response to sports world The government should play a leading role in building the mechanism of protection, inheritance and development of the traditional sports culture of ethnic minorities, realize the harmonious development of the traditional sports culture of ethnic minorities, and promote the inheritance of the traditional sports culture of ethnic minorities in excavation and collation of traditional sports programs And development.
\end{abstract}

\section{Introduction}

The traditional sports culture of ethnic minorities is one of the most important parts of China's outstanding national culture. Under the severe impact of economic globalization and modern Western sports culture and under the new situation of dramatic changes in production and life style, the traditional sports of ethnic minorities face serious practical problems in their development and inheritance. For instance, traditional sports of ethnic minorities are on the verge of extinction or have been extinct Demise, the loss of the spirit of traditional sports culture of ethnic minorities and so on. Under such circumstances, the development of traditional sports of ethnic minorities in urgent need of transformation, to adapt to the progress of society and the times, and maintain its uniqueness, can better stand in the world of sports, enrich the sports culture. Traditional ethnic minorities have rich spiritual connotation, unique nationality, tradition, recreational and fitness, and educational inheritance. They are the means to realize the educational function and the effective way to inherit the national culture. In the Sport Vocabulary, published in 1974 (Nicolas Alekse, Roman, Xiong Douyin, Lu Xianwu), published in 1974, sports culture is an integral part of a broad culture that integrates physical exercise to improve human biology and spiritual potential categories, laws, institutions and material facilities. "(1) Physical education is an important part of cultural life, a concrete manifestation of culture, and its culture shows its connotation and characteristics through sports. Yi nationality sports have its own traditional, regional and national identity, and the Yi nationality is closely related to the production and living of the Yi people. Through the Yi nationality sports, the Yi nationality culture can not only better inherit the Yi nationality culture, but also make the Yi culture more viable and vitality, but also to promote unity between the Yi people in the same village, their fellow countrymen and their ethnic groups.

\section{The basic characteristics of the traditional sports culture of ethnic minorities}

Cultural theory holds that: the cultural nationality is the commonality of any culture, and the culture of different nationalities is unique. The 55 minorities all over China's north and south have their own unique cultural traditions and their representations, which reflect the lifestyles, state of existence, religious beliefs, national psychology and national identity of all ethnic groups. The national traditional sports culture is the cultural accumulation of the people of all nationalities in our country in long-term social practice. It is an essential part of the national cultural treasure. It 
originated from the "national production struggle, military struggle, religious beliefs and life in the production and living of group tribes or ethnic groups" Entertainment "[2], or from the" production of labor, ancient military, folk customs, cultural worship and cultural life "[3], and so on, accompanied by the development of national history and national culture in the form and internal energy, to show the national spirit , Promote social exchanges, express the passion of life and cultivate the aesthetic taste of the important cultural forms. Generally speaking, the minority traditional sports culture has its basic characteristics or basic attributes as compared with the general competitive sports culture, namely, the nationality of the sports culture. Furthermore, the minority traditional sports culture is the "minority culture and sports culture" Therefore, it has the general characteristics of national culture: "nationality, entertainment, geography and diversity" or "diversity of forms, distribution of stereology and long history Sexuality, Environmental Adaptability, Ethnic Identity and Inheritance of Mysteries. "

Ethnic sports activities are the concrete manifestation of national culture. These sports are the crystallization of the collective wisdom of people of all nationalities and contain their unique aesthetic taste, spiritual value and mode of thinking. In the course of long-term historical evolution and development, the traditional ethnic sports events gradually formed on the basis of various forms of work for entertainment and education.

Traditional sports belong to the traditional arts and crafts, precept and example is its main way of inheritance. Spoken and experienced is divided into two parts: one is speech, the second is to teach. The meanings of the two are not exactly the same as the ones involved. The former gives the right to teach and the latter gives the right to teach. The emphasis of the two is different. The former focuses on imitating the movements of the preacher, while the latter focuses on the learners' Learn the technical action understanding and perception. Words and deeds are always efficient traditional sports heritage. As the Yugur people are particularly prominent, because the Yugur people do not have the characters of their own country, they can only rely on precepts and precepts in the tradition of traditional sports. From an educational point of view, there are three manifestations of this type of precept and example, namely, school education, family education and social education. In the practice of minority cultural heritage, the latter two forms of education are more obvious and have a more obvious role. In particular, the top-down transmission of family members is the most typical.

\section{Ethnic Minority Traditional Sports Culture Heritage Problems}

Our national traditional sports are rooted in the masses, circulated in the countryside, with rich agricultural and cultural features, and historically served as the main carrier of fitness, entertainment and social interaction among ethnic compatriots. In the 20th century, modern western sports gradually shift to emphasize the competitive modern sports. With the help of the Olympic Games, modern sports have swept the world with irresistible momentum. Since the 1950s, "nationwide system" in our country has ubiquitously demonstrated the concept of sports development for the purpose of obtaining the Olympic gold medal. While this policy caused the long-term development of mass sports in our country to be slow, it also led to the value orientation of national traditional sports which is more competitive and less mass. The most typical example is the gradual withdrawal of the national traditional sports "Wushu, Chinese wrestling, Go, Chinese chess and other national sports," the national games of "selecting talents for the Olympics." At the same time, the National Minority Sports Games match more and more standardized and competitive. To a certain extent, affected the echelon of national sports culture and caused the entire society to neglect the national sports culture.

Apart from the sports attributes, traditional national sports also have cultural attributes. They are both a form of fitness, athletics and entertainment, as well as an important carrier of the religious beliefs, customs, festivals, language costumes, national psychology and national culture of the Chinese nation. Since the 1950s, the traditional sports of our nation have long adopted the working mechanism of co-ordination between the heads of the sports departments, the CPC Central Committee and the education departments, and have paid great attention to the "sports attributes" of the national traditional sports while ignoring their "cultural attributes." At the same time, the lack of 
understanding of "cultural attributes" also leads to the long-standing controversy over whether traditional sports belong to "national sports" or "traditional sports", to a certain extent, this has affected the development of national traditional sports. After entering the 21st century, under the influence of the international intangible cultural heritage protection trend, a large number of traditional ethnic sports have gradually been used as cultural heritage and national folk culture as an important part of the national, provincial, city and county-level intangible cultural heritage. In 2011, "National Fitness Program (2011-2015)" put forward the following: "We should attach importance to the excavation, dissemination and popularization of ethnic traditional folk sports and carry forward the traditional national sports culture, and include the outstanding folk traditional sports in the Intangible Cultural Inheritance and protection of heritage. "The goal of extensively carrying out national traditional sports education activities, holding exhibitions and competitions of national traditional folk sports items, promoting exchanges among ethnic groups and regions, and expanding the international influence of folk traditional sports indicates that The "cultural attributes" of traditional Chinese sports have gradually gained the attention of national laws, regulations and policies.

Any kind of culture wanting to be effectively inherited and developed can not be separated from modern life. The traditional sports culture of ethnic minorities is no exception. First, one-sided emphasis on the traditional ethnic traditional sports, that traditional ethnic sports should adhere to the "original" type of protection, worried about the modernization of traditional ethnic sports will lead to the change of its traditional cultural values. This view is used in the cultural heritage of national traditional sports understandable, but can not be extended to all ethnic traditional sports. Second, it misreads and improperly develops the traditional nature of national physical education. In many places, due to lack of understanding and lack of qualified personnel, the traditional protection and modernization measures of traditional ethnic sports have become very low-level and lack of innovation. Some places seem to attach great importance to traditional sports, and competitions and activities are constantly underway. However, due to lack of innovation, lack of ornamental value and influence, the traditional ethnic sports have been developed into vulgarity regardless of time, regardless of location and cultural connotation Travel items. This kind of copy and copying, deliberately distorting the tradition of national traditional sports practices, did not effectively protect the cultural values of traditional national sports, but seriously affected the development of national physical education. Third, we mistakenly understand the modernization of national traditional sports. Simply considering that modernization is competition-oriented, westernized and Olympic-oriented, we use the various rules of the game to modernize traditional sports. The first is modernization, the modernization of ideas, and the second is the modernization of forms and content. We are now focusing on the "form" of modernization while ignoring the "God"'s modernization.

\section{Inheritance and Development of Traditional Sports Culture of Ethnic Minorities}

Firstly, we should vigorously tap the excellent culture of traditional national sports, integrate it with economic development, make rational use of market mechanisms, gradually expand investment channels, actively explore the industrialization of national sports culture and create an effective market operation mode. The second is to strengthen publicity and education of national sports culture, improve its social status. On the one hand, the introduction of national sports culture into school education, the creation of knowledgeable, performing, interesting and relatively strong project, the creation of national sports culture and education readings, audio and video data, making it an important part of the quality of education and expertise assessment, gradual Infiltration into teaching activities; the other hand, the extensive development of social education, the use of various cultural sites, bulletin boards, video room to carry out national sports knowledge and cultural knowledge, training and appreciation of cultural knowledge so that the national sports culture is effectively universal and Promotion.

As the main body of intangible cultural protection, the government plays an important role in the protection of traditional sports culture of ethnic minorities. Without policy support, the national 
sports culture will be marginalized indefinitely. It can be said that the establishment of a government-led mechanism means that the government has the responsibility to protect and nurture the national traditional sports culture. This requires the government in the excavation of relevant information, collection, collation, research, invest the necessary special funds for rescue protection. Especially the outstanding projects, stunts, descendants and masterpieces of protecting the traditional sports culture of the nation; to recreate or display things in a static or dynamic manner in various forms such as audiovisual and textual forms; further formulate the overall plan for the protection of national sports culture, strengthen legislative work and clarify the legal status of national sports culture protection.

The protection, inheritance and development mechanism of minority sports culture is the core and foundation. One of the most important reasons why the ethnic sports culture can walk from ancient times to today and its national sports cultural traditions are passed down from generation to generation is that they have long formed a complete set of self-protection, self-transmission and self-development of the national sports culture Mechanisms. This mechanism is rooted in the land of ethnic origin and has a fairly reasonable composition. At present, under the circumstance that the ethnic minorities' sports culture faces more complicated environment and is impacted by all aspects, it is even more important to protect and inherit the development mechanism of traditional sports culture of ethnic minorities.

\section{Conclusion}

Our country is a multi-ethnic country where all ethnic groups have their own unique and excellent national and cultural traditions. Under the current reality of the social transformation and the reform of the cultural system in our country, inheriting and developing the national minorities' culture in our country is an important measure for the socialist modernization and the harmonious development. As an important part of ethnic culture, the traditional sports culture of ethnic minorities is a valuable spiritual and cultural asset gradually inherited and accumulated by various national minorities in China during the long history. Inheriting, protecting and promoting the traditional sports culture of the ethnic minorities is of great value both for the protection of the national cultural heritage and for the pluralistic development of the sports culture of our country. It is an important part of our thinking on the development of "harmonious sports."

\section{References}

[1] Xia Dong, etc. Discussion on the characteristics of sports culture of ethnic minorities in China [J]. Guide, 2010 (9): 140-142.

[2] Ma Hui, Fang Zheng exploration of ethnic minority traditional sports culture [J]. Ningxia University Journal: Humanities and Social Sciences, 2006 (6): 108-109.

[3] Pang Yuanning, Jiang Shiting. The Minority Traditional Sports Culture in Southwest China Examination [J]. Journal of Beijing Sport University, 2002 (11): 735-736.

[4] Yuan Huating, Li R. The Orientation and Development of Traditional Sports Culture of Ethnic Minorities Exhibition countermeasures [J]. Journal of Wuhan University of Science and Technology, 2007 (4): 122-123.

[5] Zhong Quanhong. The types and characteristics of traditional sports culture of ethnic minorities [J]. Journal of the Western Nationalities University: Natural Science, 2008 (2): 84-85. 